\title{
Acute Osteoporosis Postpartum in a Twin Pregnancy: A Case Report
}

\author{
Illia $\mathbf{R}^{1 *}$, Guallán $\mathrm{F}^{2}$, Valencia $\mathrm{V}^{2}$, Ceretti $\mathrm{S}^{2}$, Santía $\mathrm{C}^{2}$ and Ratto $\mathrm{C}^{2}$ \\ ${ }^{1}$ Buenos Aires University, Argentina \\ ${ }^{2}$ Department of Gynecology and Obstetrics, Hospital Alemán, Argentina
}

*Corresponding author: Illia R, Professor of Obstetrics, Buenos Aires University, FACOG-FRSM Chief of Obstetrics Service Hospital Alemán, Buenos Aires, Argentina.

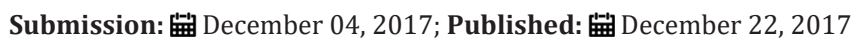

\begin{abstract}
Transient osteoporotic disease of pregnancy is a very few frequent disease but is posible that in the future we are going to see it more frequently because the increase of the age of pregnant women and the fertility treatments. We present a case of a patient with a twin pregnancy who developed a puerperal transient acute osteoporotic disease with microfractures and vertebral damage.

Keywords: Transient osteoporotic disease; Pregnancy; Puerperium; Fractures
\end{abstract}

\section{Introduction}

There is a dearth of informarion about acute postpartum osteoporosis mainly when the patient have not Received any kind of heparin. Recently, Osturk et al. [1] have informed about two cases of osteoporotic disease during pregnancy but associated to the heparin administration. He reported two cases of vertebral fractures diagnosed by Nuclear Magnetic Resonance (RMN). Both of them were diagnosed during postpartum period.

Kovacs [2] stated that when vertebral fractures happen in pregnant or lactating women, it is usually unknown whether the Case skeleton was normal before pregnancy. And itis a very important point of view according the present tendency of women to not pay attention enough to aquire the bone mass pick. In a posterior study, the same author [3] state that most women does not know her bone status before pregnancy and is not common to check this problem before pregnancy unless the patient has a previous disease that induce the physician to check it. Zangh et al. [4] also communicated recently a case of puerperal vertebral fractures in a 23 years old patient.

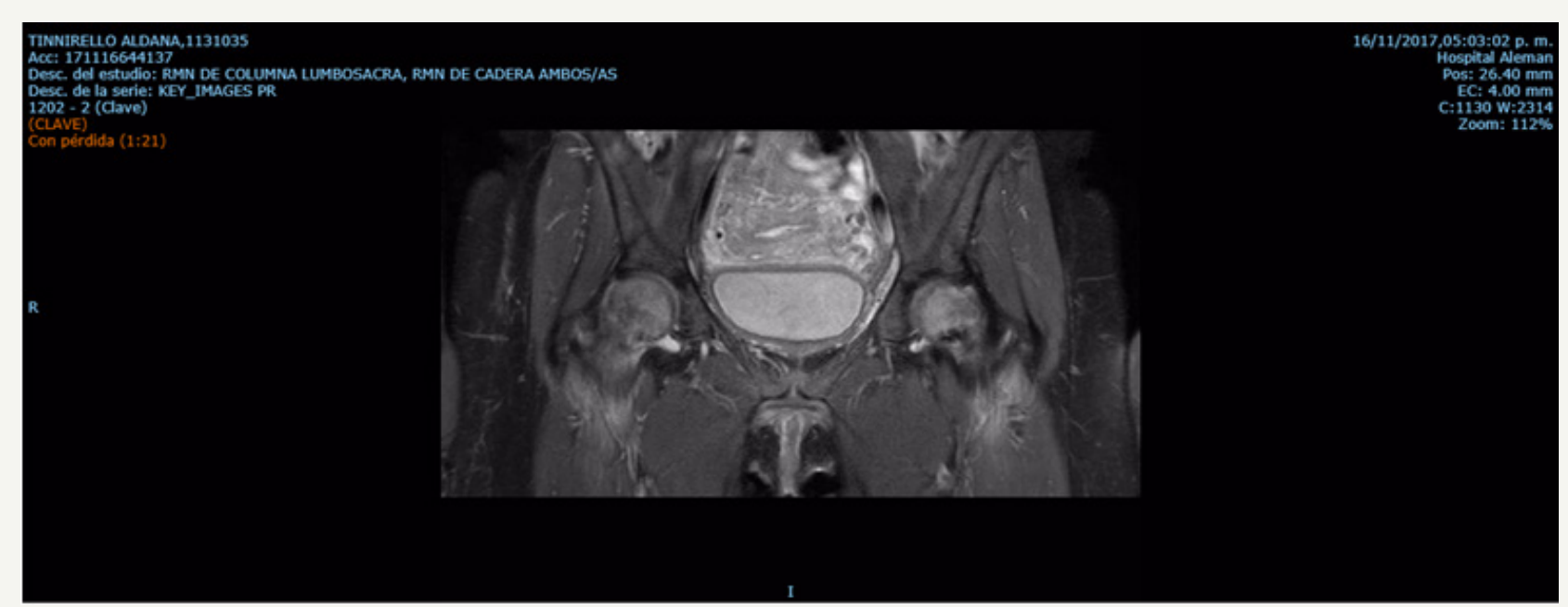

Figure 1: Bonemarrow edema. 


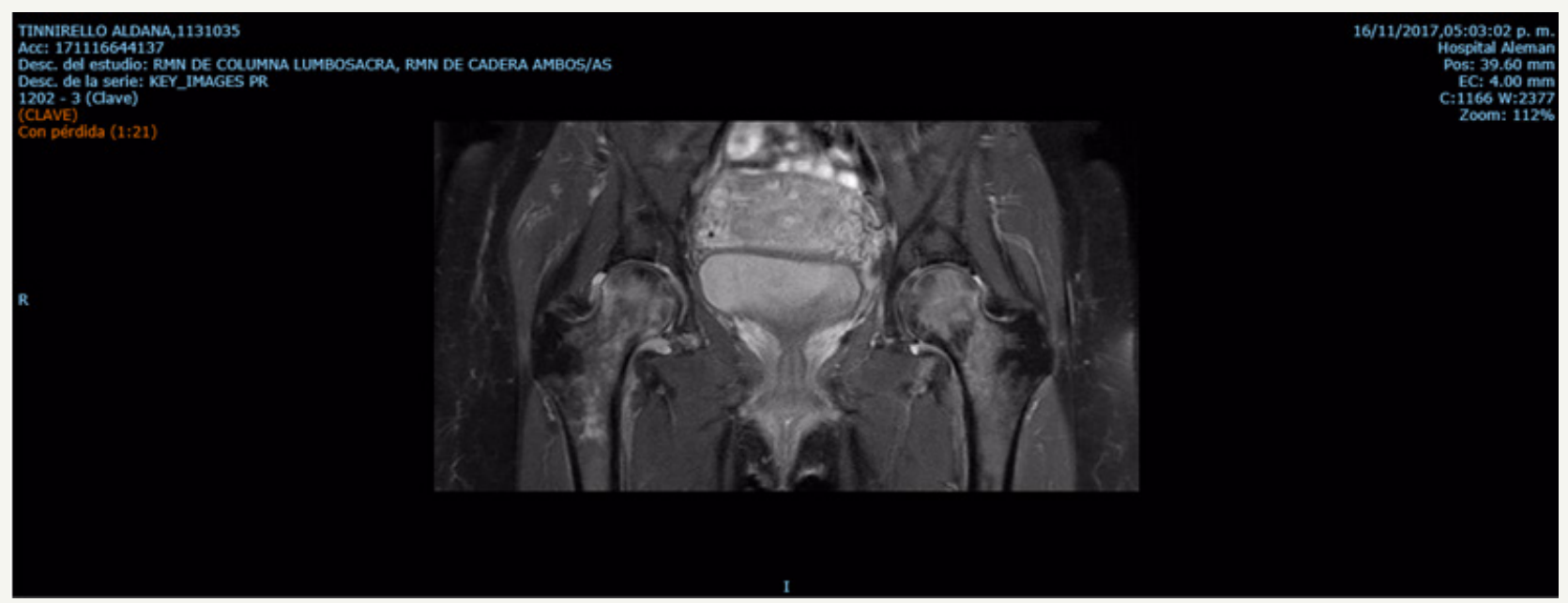

Figure 2: Bonemarrow edema and discal protrusión in L5.

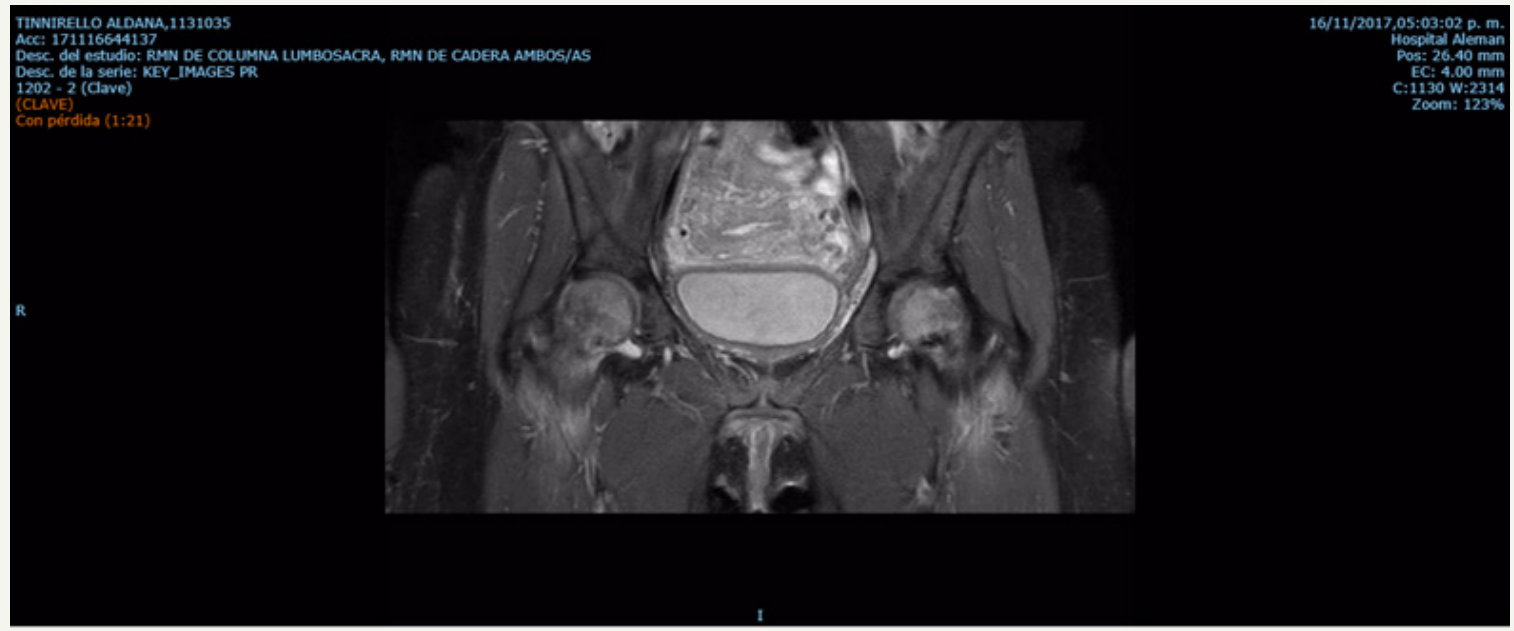

Figure 3

A 32 years old patient booked prenatal control at 8 pregnancy week's. She does neither have any pathological background nor developed a disease that warranted the heparina dministration. At her first ultrasound, it was found a twin pregnancy bichorial and biamniotic. There were no problems during pregnancy evolution and shereceived a multi vitamin supplements specific for pregnancy plus calcium supplement and iron during all pregnancy. According the guidelines for twin pregnancies in our Service, we scheduled a labour induction during 37 pregnancy week. But, the first fetus was found on the breech presentation so we had to perform a cesarean section under spinal anaesthesia. The new borns did well with a $2940 \mathrm{~g}$ the first and $3090 \mathrm{~g}$ the second weight. The evolution of the new borns was completely normal. By the first postoperatory day, the patient started to complain of pain impress a sciatic nerve compromise. She only could move under analgesics but without pain killers she could not move. We call the rheumatologists to check the possibility of some bone complication and they performed a RMN that showed usa minimal discal protrusion in L5, edema of bonemarrow at both femur bones with trabecular micro fractures.
The final diagnosis was transient osteoporosis of pregnancy with bonemarrow edema syndrome (Figures 1-3). The indications were: rest, analgesics and LMWH because of the rest with following by the Rheumatology Service. The patient was discharged without the possibility to walk by herself and she come to the first puerperal control one week later in a wheel chair. The post operative evolution was uneventful. All the blood tests were normal including calcium levels and parathormone levels.

\section{Comment}

As we said in the introduction, is very weird that the prepregnant patient under went to check their bone status at the preconceptional appointment. Besides, according the new tendencies of a young women, a very few attention is lend to the bone mineral status and they do not have take in account to acomplish with to reach the bone pick in herthirties. Another very important thing is that the possibility of acute transient osteoporosis of pregnancy become in a more frequent disease according the increase in the age of the women becoming pregnant, and as a consequence of the increase in 
Fertility treatments, the rate of multiples is rising with a almost 3\% of all pregnancies. We have treated patients with different levels of transient osteoporosis after pregnancies with thrombophilias that received $\mathrm{LMWH}$, but this is the first case of a patient without this drug to develop the disease. We have to pay more attention when a patient in the immediate puerperium complains of boneor articular pain and specially when the patient can not walk without pain killers. In this cases is warranted to check what is going on with her bones, because without the right treatment, the microfractures can become in a more serious bone harm with unexpected consequences.

\section{References}

1. Ozturk G, Akpinar P, Karamanlioglu AD, Ozkan FU, Aktas I (2017) Pregnancy-related osteoporotic vertebral compression fractures in two patients treated with low-molecular-weight heparin during pregnancy: case reports. Gynecol Endocrinol 26: 1-3.

2. Kovacs CS (2014) Osteoporosis presenting in pregnancy, puerperium and lactation. Curr Opin Endocrinol Diabetes Obes 21(6): 468-475

3. Kovacs CS, Ralston SH (2015) Presentation and management of osteoporosis presenting in association with pregnancy or lactation. Osteoporos Int 26(9): 2223-2241.

4. Zhang M, Chen P, Li B, Du J, Pan T, et al. (2017) Approach to the patient with pregnancy and lactation-associated osteoporosis: A case report and a review of the literature. Medicine 96(46): e8671. 